\title{
Multidimensional measurement of precarious employment using hedonic weights: Evidence from Spain ${ }^{*}$
}

\author{
Carmelo García \\ Universidad de Alcalá \\ Mercedes Prieto-Alaiz \\ Universidad de Valladolid \\ Hipólito Simón \\ Universidad de Alicante-Instituto de Economía Internacional
}

\begin{abstract}
This article examines employment precariousness in Spain based on multidimensional precarious measures in the framework of the counting approach proposed by Alkire and Foster (2007 and 2011). The methodological novelty of our approach consists of the use of hedonic weights derived from the subjective evaluation of the determinants of job satisfaction by employees for the selection and the quantification of the influence of the dimensions of jobs that make up multidimensional precariousness indices from the perspective of low-quality jobs. The evidence obtained confirms that the precariousness of the employment created in Spain intensified significantly in the aftermath of the economic crisis and intense labour reforms. Moreover, it suggests that although the temporary nature of employment is the most salient component of employment precariousness from a multidimensional perspective, a broad set of job attributes negatively associated with job satisfaction should be considered in the multidimensional measurement of employment precariousness.
\end{abstract}

Keywords: Employment precariousness; quality of employment; multidimensional indicators; counting approach; Spain.

JEL Codes: J20, J21, J28, J80.

\section{Introduction}

Precarious employment is currently considered one of the most crucial and challenging issues in employment policy and labour-related studies (see e.g. ILO, 2011 and Kalleberg, 2009). The relevance of this phenomenon is explained inasmuch precarious jobs can become a permanent trap and not a means of accessing the labour market (Lewchuk et al., 2016) and lead, inter alia, to poor physical and mental health and high levels of stress (Benach et al., 2014). Moreover, employment precariousness is apparently becoming more widespread in the labour market, very specially since the onset of the Great Recession (for more details, see European Union, 2016; OECD, 2015, and UNECE, 2014), and it is particularly intense in certain countries, periods of time, and particular groups of workers, such as young people, women or immigrants (see e.g. Fudge and Owens, 2006; Bhalla and McCormick, 2009; Porthé et al., 2010). In this vein, precarious

\footnotetext{
* This work was supported by the Spanish Ministry of Economy and Competitiveness under grants CSO2017-86474-R, CSO2014-55780-C3-2-P and ECO2016-77900-P, by ERDF and by Autonomous Community of Madrid and European Commission (Project S2015/HUM-3416-DEPOPOR-CM).
} 
jobs are blocking opportunities particularly for young people, who suffer more the greatest burden of insecure and poor-quality jobs, increasing the risk of falling into poverty (Bradley and van Hoof, 2005; Pizzuti, 2009; Kretsos, 2010). Furthermore, very significant differences are found between countries in the scope and determinants of the phenomenon (Kretsos and Livanos, 2016).

From the specific perspective of management and human resources, there exists abundant evidence that the low quality of jobs influences the environment in the workplace and the level of employee motivation, absenteeism, subsequent performance and productivity (Royuela and Suriñach, 2013; Boxall, 2013; Campbell and Price, 2016). These negative impacts could be particularly intense in new business models, as different studies highlight the link between new modes of business organization and new forms of employment (Frade and Darmon, 2005, Edwards and Ram, 2006, Edwards et al., 2009, Campbell and Price, 2016).

However, despite the interest that precarious employment has received in the literature, there is currently no agreed definition commonly accepted on what precarious employment exactly is. At first, the very concept of employment precariousness is rather vague, as it can refer to very different questions, such as the precariousness of jobs, the precariousness of workers (according to their overall personal circumstances), or even the consideration of precariousness as a social class (for more details see Campbell and Price, 2016). Although focusing on the precariousness of employment according to the attributes of the jobs is the most common approach in the literature, there is no shared approach in this vein either. Thus, while many studies focus on the lack of stability/security or the 'atypicality' of jobs (Vosko, 2002 and 2006), a rather common perspective to identify employment precariousness focuses on the poor quality of jobs (Rodgers and Rodgers, 1989; Kalleberg, 2009 and 2011; Fullerton et al., 2011). ${ }^{1}$ On the contrary, a certain consensus can be found as to consider employment precariousness as a multi-faceted phenomenon, so that previous studies have systematically addressed their analysis from a multidimensional perspective, regardless of the specific approach chosen (see e.g. Olsthoorn, 2014 and Kretsos and Livanos, 2016).

In this context, there is a clear need of developing new research on the definition and measurement of job precariousness in order to design appropriate economic policy measures that help reduce it and fostering the creation of quality jobs (OECD, 2015). Accordingly, the aim of this article is to examine employment precariousness in Spain on the basis of a new method of constructing multidimensional precariousness measures.

In line with a rather common approach in the literature to employment precariousness, we use a multidimensional perspective focused on poor-quality job dimensions. More specifically, our working definition of precariousness is based on the consideration that

\footnotetext{
${ }^{1}$ A cognate approach can be found related to job quality. As a matter of example, fostering job quality is a central element of the new OECD Jobs Strategy (OECD, 2018). A review on the development of concepts related to the quality of employment in the academic literature can be found in Burchell et al. (2013).
} 
employment precariousness can be defined as a multidimensional construct that reflects the labour dissatisfaction of workers who simultaneously face deficiencies in different objective dimensions of their jobs which reflect poor working conditions. Although the concept of precariousness is usually considered to have a general validity across different cultures or countries, ${ }^{2}$ the aforementioned relevant differences observed across economies in the scope of the phenomenon suggest that different dimensions could have a different influence according to specific labour and institutional factors. As a result, we consider that precariousness is a psychological reality perceived as a confluence of job deficiencies, and that the election of the dimensions and their relative weights should be related to the perceptions of workers in the relevant national/institutional specific context.

In this vein, the article seeks to contribute from a methodological point of view to lessening some shortcomings in the previous literature on employment precariousness. Our novel proposal for the analysis of the phenomenon consists of the construction of multidimensional indexes of precariousness through an adaptation of the counting approach methodology of Alkire and Foster (a precedent can be found in García-Pérez et al., 2017), with the novel use of hedonic weights. Overall, this methodology allows the phenomenon of precariousness to be analysed through indicators that quantify aspects such as the incidence and intensity of precariousness from a multidimensional perspective, and determining the separate contribution to total precariousness of each individual job attribute. The novel use of hedonic weights permits in particular that both the selection of the dimensions of jobs that make up multidimensional precariousness and the quantification of their relative influence are derived from the subjective valuation by employees, avoiding, as a consequence, the discretionary choice of dimensions of precariousness. This is particularly interesting, inasmuch as certain job characteristics which could be identified discretionally as drivers of precariousness by researchers are often associated with certain flexible forms of work voluntarily accepted by workers (Barbier, 2011; Campbell and Price, 2016). On the other hand, it is worth noting that this flexible approach enables the concept of precariousness to be adapted to the context of each specific labour market through the subjective valuation of workers. This is particularly relevant as both the perception of what constitutes precarious employment and the determinants of job satisfaction vary widely across countries (Fullerton et al., 2011; Borooah, 2009; Westover, 2012; Westover and Taylor, 2010).

The methodology based on the construction of multidimensional indexes with a dual approach is applied to the study of the scope and the evolution of employment precariousness in Spain between 2006 and 2015. Multidimensional indicators of precariousness are constructed using two databases, one with information about objective dimensions of the job positions and another which enables to examine the impact of these dimensions on job satisfaction, and the analysis focuses on newly-created jobs, given that

\footnotetext{
${ }^{2}$ In spite of the fact that, as suggested by an anonymous referee, employment precariousness and its dimensions may have different meanings to people of different countries, so that a caveat must be made about the assumption of construct equivalency for employment precariousness across different countries or cultures.
} 
it better reflects changes in the scope of precariousness employment. Spain constitutes a very interesting case study for employment precariousness for several reasons. Firstly, because it has traditionally suffered a high relative incidence of this phenomenon, with international comparative analyses suggesting that Spain exhibits the highest incidence of precariousness employment all over Europe (Kretsos and Livanos, 2016). Secondly, because there are different factors that could have possibly fostered the incidence of precariousness in the period examined (2006-2015). One factor is the strong deterioration of the Spanish labour market during the intense double-dip recession initially associated to the Great Recession and later to the crisis of the peripheral economies of the Euro zone (as a result, the unemployment rate in Spain more than tripled in that period, increasing from $8 \%$ to $26 \%$ ). Another factor is related to the intense regulatory changes which increased labour flexibility and reduced the protection provided to workers through the application of successive reforms of the labour market, the one approved in 2012 being particularly intense (for more details, see OECD, 2013).

In particular, the article tries to answer the following research questions: i) which job attributes should be considered in the definition of employment precariousness?; ii) should all the dimensions of precariousness have the same relative importance/weights when examining the phenomenon?; and iii) how has employment precariousness evolved in Spain in the aftermath of the economic crisis and the application of intense labour reforms?

In a nutshell, the evidence obtained shows that a broad set of job attributes are negatively associated with the job satisfaction of workers and that, accordingly, the rather limited set of attributes usually considered in the previous literature (namely temporary contracts, low wages and involuntary part-time work) should be extended to include additional job characteristics such as over-qualification or undesirable working hours. Moreover, according to the subjective valuation of Spanish workers, the job dissatisfaction associated to the incidence of certain elements, such as extended hours or, very especially, fixed-term contracts, is particularly intense and, as a result, they should be prominent components of the measurement of multidimensional precariousness. This is relevant, inasmuch as the use of hedonic weights gives rise to significant differences in practice in the examination of precarious employment in Spain, as opposed to the alternative of using the same weights for all the dimensions. As regards the scope and the evolution of the phenomenon in the Spanish economy, the evidence confirms that the overall incidence of precarious employment from a multidimensional perspective is significant all over the period examined, and reveals that the precariousness of jobs created in Spain intensified significantly in the aftermath of the crisis and the intense regulatory changes in the labour market. Furthermore, it confirms that the strong temporary nature of employment is the most salient component of precariousness from a multidimensional perspective.

The article is structured as follows. The following section presents a discussion of the literature on precarious employment. In the third section the methodological proposal for examining employment precariousness is presented. The two data sources used in the 
empirical analysis and the selection of the dimension of employment precariousness are described in the fourth section. The results obtained in the analysis of the phenomenon in Spain between 2006 and 2015 are presented in the fifth section, and the article finishes by drawing the main conclusions.

\section{Literature review}

\subsection{General literature}

Despite the interest that precarious employment has received in the literature, and the attempts of different studies framed in sociology, economics or business literature of proposing a common definition of precariousness related to a solid measurement methodology (see e.g. Olshtorn, 2014 and Kretsos and Livanos, 2016), there is currently no agreed definition commonly accepted on what precarious employment is. The term precariousness is mentioned originally in Pitrou (1978), linked to the type of work contract, as well as to such general aspects as the lack of skills, uncertainty, health problems or the situation of the worker in his broader social relations. This sociological base, which broadens the focus of economic and business studies, influenced the seminal work of Rodgers and Rodgers (1989), who defined precarious employment as the combination of factors that impede a level of decent life, such as instability, insecurity and social and economic vulnerability, and pointed out that the limits of the concept are diffuse and changing according to each specific society.

The approach of Rodgers and Rodgers (1989) is a basic reference for studies on precarious employment of institutions such as the European Commission (European Commission, 2011 and 2017; McKay et al., 2012) or the ILO (2011), in which precariousness is mainly associated with job insecurity caused by the temporality and unpredictability of the employment relationship. These dimensions of precarious employment were developed and expanded in the reference works of Fudge (1997), Vosko (2002 and 2006), Kalleberg (2009) and Fullerton et al. (2011), where the 'atypicality' of jobs regarding a usual standard job and the quality of jobs are both used to identify precarious employment. It is worth mentioning that the aforementioned studies systematically focus on the multidimensional nature of the concept, which leads to the proposal of different definitions of precariousness depending on dimensions and weights that are chosen discretionally.

As regards to the specific dimensions of precariousness usually considered in the examination of precarious employment, previous studies have focused traditionally on fixed-term contracts, working part-time and earning low wages (see e.g. Kranh, 1995; Polivka, 1996; Quinlan et al., 2001; Leschke et al., 2008; or Olsthoorn, 2014). The choice of these dimensions is justified given that they are clearly associated to a greater unpredictability of the duration of the employment relationship and/or poorer working conditions (see e.g. Guadalupe, 2003 and Comi and Graseni, 2012 for temporary employment; Hirsch, 2005 and Fernández-Kranz et al., 2014 for part-time work; and 
Fudge, 2009 and Barbier, 2004 for low-paid jobs). Yet, although these three dimensions have represented the basic core of precariousness dimensions, more recent research has focused on new dimensions of precarious employment. Thus, as a matter of example, Evans and Gibb (2009), McKay et al. (2012), OECD (2015), and Arranz et al. (2018) open the range of factors to other characteristics of employment (related, among others, to the excessive prolongation of the working day, hazardous work, at night or on weekends, the absence of training received in the company, the relationship with the controls or the flexibility, and ability to predict schedules) showing, in short, the lack of consensus in the literature about what characteristics make up a precarious job.

A set of studies have delved specifically into the determinants and consequences of precariousness. In particular, they examine how precarious employment is affected by new forms of contracts derived from the flexibilization under legislative changes (Tangian, 2008; Burroni and Keune, 2011; OECD, 2015); the generalization of subcontracting and outsourcing (Perulli, 2003; Evans and Gibb, 2009); and the effect of economic crises through increased unemployment (Kretsos, 2010). In a similar vein, they analyse the effect of belonging to specific groups such as young people (Bradley and van Hoof, 2005; Kretsos, 2010); women (Fudge and Owens, 2006; Bradley and Healy, 2008; Sheen, 2010); workers hired through temporary employment agencies (Elcioglu, 2010; Arranz et al., 2018); older workers (D'Amours, 2010); immigrants (Bhalla and McCorick, 2009; Porthé et al., 2010); or employees in certain sectors (Perulli, 2003; Ross, 2009). International comparisons of employment precariousness are, on the other hand, rather scarce. Among the main exceptions, Kretsos et al. (2016) compares the precariousness of employment across the European Union, finding that precarious employment is more prevalent in certain countries (such as Mediterranean countries). The use of comparative indicators on job quality to allow comparisons among countries in a common framework is also a central element of the recently reformulated OECD Jobs Strategy, where this institution recommends fostering job quality as a central policy priority (OECD, 2018).

\subsection{Business literature}

Low-quality jobs have also been examined in the business literature, among other reasons, because of their impact on human resources management. Indeed, human resource managers face the consequences of precarious jobs, which cause a lack of motivation that reduces productivity and negatively influences job performance and the workplace environment (Koonmee et al., 2010; Lee et al., 2013; Royuela and Suriñach, 2013; Boxall, 2013; Campbell and Price, 2016). Different studies have also been conducted on the influence of ethical values on the quality of life at work and business results, based on the opinions of different types of managers such as human resource managers (Koonmee et al., 2010) or marketing managers (Marta et al., 2013). Many studies of business literature focus on the analysis of the quality of work life, studying its relationship with productivity losses related to absenteeism and several occupational diseases that reduce the health and well-being of employees (Horst et al., 2014). Besides, part of this research addresses the specific problem of the poor quality of jobs in the new 
business models (Frade and Darmon, 2005; Edwards and Ram, 2006; Edwards et al., 2009; Campbell and Price, 2016).

Job satisfaction, which is an essential issue in the approach to the design of the multidimensional indicators proposed in this article, has been also the subject of different studies of business literature from the seminal works of Vroom (1964) and Hunt and Saul (1975). Accordingly, different studies have examined the consequences of job satisfaction/dissatisfaction on a broad range of questions, such as productivity (Appelbaum and Kamal, 2000); the quality of work (Tietjen and Myers, 1998); competitiveness and success of companies (Garrido et al., 2005); or absenteeism and the decision of leaving a company (Lee, 1998). Although general models of job satisfaction have been proposed (e.g. Kalleberg, 1977), it is difficult however to find in practice models that can be generalized in all countries, so it is usually considered that the results of studies on job satisfaction for different countries should be compared with great caution, and that an expanded model of job satisfaction that takes into account countrycontextual differences is needed (see e.g. Westover 2008 and 2012). Accordingly, in the business literature in particular, some studies have confirmed clear cross-national differences in job satisfaction and their determinants (Handel, 2005; Westover, 2008, 2011, 2012; Westover and Taylor, 2010). The results of these studies are an important base of the flexible methodology proposed in this article, which permits to adapt the precariousness concept to different countries, cultural contexts or groups, using hedonic weights that capture the perceptions of job dissatisfaction for the relevant group of workers.

\section{Methodology}

This section presents the approach to measuring job precariousness constructing multidimensional indicators based on the application of the counting approach methodology proposed by Alkire and Foster (2007 and 2011) using hedonic weights. In short, the starting point for applying this methodology is the selection of the dimensions of the jobs associated to employment precariousness and the election of thresholds that permit identifing in each of them the presence of drawbacks in the job. Subsequently, a multidimensional precariousness indicator is calculated for each job that measures its total number of deficiencies (weighted according to the weight previously established for each dimension of precariousness). Comparing the value of this indicator with a reference cut-off permits to determine subsequently whether each job is precarious from a multidimensional perspective. Next, information on individual jobs is aggregated into measures of precariousness that estimate the incidence of precarious employment and its intensity for the total working population. Finally, orderings of multidimensional precariousness that guarantee the robustness of the results to the indicator of precarious employment and the threshold used are presented, proposing a statistical test for multiple comparisons. 


\subsection{Selection of the dimensions of employment precariousness and their weights}

The construction of an indicator that permits to identify whether a drawback exists in each job first requires the selection of the dimensions of employment that are associated to precariousness, together with the variables that enable them to be measured. A specific threshold should also be established for each dimension, below which a job is deemed to have deficiencies. Therefore, if $X_{i j}$ is the observation of job $i$ in dimension $j$ with $i=1, \ldots$, $N$ and $j=1, \ldots, D$ and $Z_{j}$ is the threshold established in dimension $j$, then job $i$ has a deficiency in dimension $j$ if $X_{i j}<Z_{j}$. For the specific case of dichotomous qualitative variables, a job is deficient in the dimension estimated by the variable if it fulfils a certain condition (such as having a fixed-term contract or working part-time).

Once simple indicators have been constructed for each dimension and the corresponding weights have been assigned to each of them, the indicator $P$ (weighted precariousness count) is defined as a synthesis of the total number of (weighted) deficiencies of job $i$ as follows:

$$
P_{i}=\sum_{j=1}^{D} w_{j} I_{i j} \text { for } i=1 \ldots N
$$

Where $I_{i j}=I_{\left\{X_{i j}<Z_{j}\right\}}$ is the indicator function, which takes the value of 1 if the condition in brackets is true and 0 in the rest of cases; $w_{\mathrm{j}}$ is the weight assigned to each indicator and $N$ is the total number of jobs. The weights are standardised so that their sum is equal to the total number of indicators $D$, so that $P_{i}$ takes values of between $O$ and $D$ (being $O$ the value associated to a job that is not considered as precarious in any aspect and $D$ the value associated to a job that is precarious in every dimension). Meanwhile, the weights $w_{j}$ enable each dimension to be weighted in accordance with the relative importance attributable to this dimension.

Although the selection of weights to each dimension in the construction of multidimensional indices is highly relevant (among other circumstances, because the weights play an important role in the determination of the trade-offs between the dimensions), there is no consensus in the literature with respect to the criterion that should be adopted. ${ }^{3}$ Within a context where the different types of criteria can be grouped into those based on the empirical evidence (data-driven), those derived from normative criteria and hybrids of the former (Decancq and Lugo, 2013), the method chosen in this study to assign the relative weights of each dimension corresponds to a hybrid criterion, based on the estimate of hedonic weights using a multivariate analysis of the factors that affect the job satisfaction of the workers. This method enables us to combine information from

\footnotetext{
${ }^{3}$ An exhaustive review of the different criteria used in the literature for establishing the relative weights can be found in Decancq and Lugo (2013) and a review of the criteria used in general for the construction of multivariate indices in Nardo et al. (2005).
} 
different databases regarding the real distribution of the characteristics of the jobs with the scores that the individuals give to these attributeset al.. ${ }^{4}$

The identification of precarious jobs from a multidimensional point of view requires the establishment of a threshold, $k$, so that a job $i$ is considered to be precarious if $P_{i} \geq k$. In practice, different multidimensional cut-offs can be used between the extreme criteria of considering, on one hand, that a job is precarious if it has deficiencies in a single (weighted) indicator ( $k=\min \left\{w_{1}, \ldots, w_{D}\right\}$; union approach), or requiring, on the other hand, deficiencies in all the indicators ( $k=D$; intersection approach). In this study we have opted to use as a general approach a threshold equivalent to half of the dimensions considered $(k=4)$. It is worth pointing out that, in any event, the comparisons made in the final part of the analysis permits to confirm the robustness of the evidence obtained to the changes in the multidimensional precariousness threshold $k$.

\subsection{Aggregate measures of multidimensional employment precariousness}

From an aggregate point of view, the overall incidence of precariousness in the employed population is measured using the multidimensional precariousness rate, $H$ :

$$
H=\frac{\sum_{i=1}^{N} I_{i}}{N}
$$

Where $I_{i}=I_{\left\{P_{i} \geq k\right\}}$ is an indicator function which takes the value of 1 if the individual job $i$ is considered as being precarious on a multidimensional level (that is, if $P_{i} \geq k$ ). Consequently, $H$ shows the proportion of total jobs that are precarious from a multidimensional perspective.

The intensity of precariousness is measured using the average number of deficiencies in the multidimensional precarious jobs, $\mu_{P}$ :

$$
\mu_{P}=\frac{\sum_{i=1}^{N} I_{i} P_{i}}{\sum_{i=1}^{N} I_{i}}
$$

This indicator is standardised in reference to the maximum number of dimensions in which a job can be precarious. Consequently, the intensity of the precariousness of precarious jobs in the overall working population can be quantified by the standardised mean, $A$ :

$$
A=\frac{\mu_{P}}{D}
$$

\footnotetext{
4 See, for example, Schokkaert (2007) and Nardo et al. (2005) for similar analyses related to the determinants of life satisfaction of individuals. In this sense, it is worth highlighting that although there is some precedent of the use of job satisfaction expressed subjectively in order to adjust the objective estimates of the job quality (Schokkaert et al., 2011), as far as we know, this is an essentially a new feature in the analysis of employment precariousness.
} 
Finally, the adjusted multidimensional precariousness rate $\left(M_{0}\right)$ combines both the incidence and the intensity of precariousness. This indicator is defined as the total weighted sum of deficiencies of multidimensional precarious jobs $\left(\sum_{i=1}^{N} P_{i} I_{i}\right)$ divided by the maximum number of deficiencies that all the jobs could exhibit (the product of $N$ and $D$ ), and corresponds, alternatively, to the product of $H$ and $A$ :

$$
M_{0}=\frac{\sum_{i=1}^{N} P_{i} I_{i}}{N D}=H A
$$

A relevant characteristic of $M_{o}$ is that it is decomposable by dimensions and population subgroups (for more details, see Alkire and Foster, 2011), which permits to examine the causes of overall precariousness based on the contributions of the different dimensions or population subgroups to the indicator ${ }^{5}$.

\subsection{Orderings of multidimensional employment precariousness}

The final step in the approach proposed for the analysis of employment precariousness is based on examining the robustness of the differences observed in the comparison of employment precariousness between different job distributions with respect to variations in the cut-off value of multidimensional precariousness $(k)$ and in the multidimensional indicators of precariousness.

This is done applying the theoretical results of Lasso de la Vega (2010) regarding the dominance of functions. The tests derived from these results permits specifically to infer the relationship between the aggregate multidimensional precariousness measures of two populations based on the comparison of their FD curves (first dominance curves), which represent the multidimensional precariousness rate $H$ for all the possible multidimensional cut-offs of precariousness $k$ values ranked in a decreasing order of the value $k$ :

$$
F D(l)=H_{D-l} \quad l \in[0, D]
$$

Specifically, if $F D_{A}$ is the $F D$ curve of a population of jobs A (corresponding, for instance, to a particular year) and $F D_{\mathrm{B}}$ is that of a population $B$ where $F D_{A}(l) \geq F D_{B}(l)$ for all the admissible values of $l$, the adjusted precariousness rates of both populations obey $M o_{A}(k)$ $\geq M o_{B}(k)$, for all cut-off $k$ from $l \in(0, D]$ (Lasso de la Vega, 2010). ${ }^{6}$

In order to apply this procedure in a context using samples, a hypothesis test is carried out which permits to compare the ordinate vectors of the $F D$ curves, $H=$

\footnotetext{
5 Throughout the analysis each of the multidimensional measures of precariousness is estimated consistently with its analogous sample estimator $\left(\widehat{H}, \hat{A}\right.$ and $\left.\widehat{M}_{o}\right)$, with its asymptotic distributions having a normal distribution (Yalonetzky, 2011).

6 This result can be actually extended to a broad family of multidimensional indicators of Alkire and Foster's methodology which satisfy a series of elemental axioms, including Mo (Lasso de la Vega, 2010).
} 
$\left(H_{k_{1}}, \ldots, H_{k_{j}}, \ldots, H_{k_{m}}\right)$, which contain the multidimensional precariousness rates for all the possible points of $k\left(k_{1}, \ldots, k_{j}, \ldots, k m\right)$ in the two populations $A$ and $B$, with the objective of testing hypothesis $H_{0}: \boldsymbol{H}^{A}=\boldsymbol{H}^{B}$ vs. $H_{A}: \boldsymbol{H}^{A} \neq \boldsymbol{H}^{B}$.

So as to examine whether the difference between vectors $\boldsymbol{H}$ of the two populations is statistically significant, a procedure based on a multiple comparison test proposed by Bishop et al. (1991) is used in order to test the first and second order stochastic dominance. To this end, it is assumed that two independent samples are used. Initially, we wish to test the equality of the multidimensional precariousness rate for a specific multidimensional threshold in two populations $A$ and $B$, in order to test $H_{0, j}: H_{k_{j}}^{A}=H_{k_{j}}^{B}$ vs. $H_{A, j}: H_{k_{j}}^{A} \neq H_{k_{j}}^{B}$. Taking the results of Yalonetzky (2011) into account, under the null hypothesis, the asymptotic distribution of the following statistic:

$$
T_{j}=\frac{\widehat{H}_{k_{j}}^{A}-\widehat{H}_{k_{j}}^{B}}{\left(\widehat{H}^{*}\left(1-\widehat{H}^{*}\right)\left(1 / n^{A}+1 / n^{B}\right)\right)^{1 / 2}}
$$

is a standard normal distribution, where $n^{l}$ is the sample size with $l=A$ and $B$ and $\widehat{H}^{*}=$ $\frac{n^{A} \widehat{H}_{k_{j}}^{A}-n^{B} \widehat{H}_{k_{j}}^{B}}{n^{A}+n^{B}}$

The general null hypothesis $\left(H_{0}: \boldsymbol{H}^{A}=\boldsymbol{H}^{B}\right)$ is the intersection of hypothesis $H_{0, j}$ and the alternative general hypothesis $\left(H_{A}: \boldsymbol{H}^{A} \neq \boldsymbol{H}^{B}\right)$ is the union of $H_{A j}$. In order to control the level of overall significance for the number of comparisons, each of the statistics $T_{\mathrm{j}}$ is compared with the values of the distribution of the studentised maximum modulus (SMM) variable with $m$ and infinite degrees of freedom (the critical values of SMM can be found in Stoline and Ury, 1979).

If $H_{0, j}$ cannot be rejected in the comparisons of the distributions $A$ and $B$ for every $j$, then the hypothesis that the precariousness of the compared job distributions is equal is not rejected. In the case where the null hypothesis as a whole is rejected, if for some values of $k$ significant positive differences are detected $\left(H_{k_{j}}^{A}>H_{k_{j}}^{B}\right)$ and for others significant negative differences are observed $\left(H_{k_{j}}^{A}<H_{k_{j}}^{B}\right)$, there is no dominance between the distributions and, therefore, comparative conclusions regarding the employment precariousness of populations $A$ and $B$ cannot be established. On the contrary, there will be dominance of one distribution over another only if significant positive differences are detected either for all the values of $k$ (strong dominance) or for some of them (weak dominance), which implies that for any multidimensional precariousness cut-off $k$, this distribution suffers from greater employment precariousness in terms of different multidimensional indicators of precariousness, including the adjusted multidimensional precariousness rate $\left(M_{0}\right)$. 


\section{Data and selection of dimensions of employment precariousness}

\subsection{Data sources}

The main data source in which the empirical analysis is based is the Encuesta de Población Activa [Labour Force Survey] (hereafter, EPA), published by the Spanish National Statistical Office. It is the most complete source of information for Spain with information about the working conditions of employees for a broad time period and rich enough to enable the appropriate measurement of employment precariousness on a multidimensional level. The EPA is a survey addressed to households with the main objective of obtaining information related to the labour market. Its design is based on the definitions and criteria established by the International Labour Organization, which enables homogeneous comparisons with data from other countries. In practice, the microdata of the annual sub-sample of the survey have been used (made up of approximately 40,000 households interviewed), given that this allows for the measurement of a very broad group of job attributes potentially related to precariousness. The analysis covers the period 2006-2015 and is limited to employees who do not work in the armed forces. The sample for the pool of the ten years is made up of 319,079 employees.

Alternatively, the Encuesta de Calidad de Vida en el Trabajo [Survey on Quality of Life at Work] (hereafter ECVT), has been used to calculate the hedonic weights related to the different dimensions in creating the multidimensional precariousness indicators. The ECVT is a survey that was conducted by the Ministry of Employment and Social Security annually until 2010 and is composed of independent cross-sections for each year with a size of around 8,000 workers. The objective of the survey is to provide detailed information about the characteristics of employment, including very extensive information about individual and family characteristics of the workers, the objective characteristics of their jobs and the subjective characteristics perceived about them (including overall job satisfaction)., The pool of the cross-sections of the waves of the ECVT between 2006 and 2010 has been used for the analysis and the final sample is made up of 25,964 employees.

\subsection{Selection of the dimensions of employment precariousness}

The choice of the characteristics of the jobs which are associated to employment precariousness and the quantification of the relative weighting of each dimension has been carried out based on the ECVT, through the ordinary least squares estimation of a model in which the dependent variable measures the degree of satisfaction expressed by the individual in relation to his/her job (measured on a scale of 0 to 10, growing with the level of satisfaction). ${ }^{7}$ A full set of characteristics of the jobs traditionally highlighted in

\footnotetext{
${ }^{7}$ Although it is generally accepted that, for both theoretical and empirical reasons, it is preferable that any variable that measures satisfaction expressed subjectively is treated as ordinal, the fact that in this case job satisfaction is measured with a high number of categories enables it to be treated as a continuous cardinal variable (Stutzer and Frey, 2008). Previous studies suggest that this choice leads to results very similar to
} 
the literature as related to undesirable attributes of jobs and contained in the EPA are included as explanatory variables due to their potential relationship with precariousness. ${ }^{8}$ These include earning a relative low wage (defined as earning an hourly wage lower than $60 \%$ of the average wage of the economy); having a fixed-term contract; working parttime involuntarily due to not having been able to find a full-time job; frequently working longer hours than agreed or than those established in the contract or in a collective agreement; frequently working at night, Sundays or shifts, respectively; being overqualified (this situation is identified through an objective approach, corresponding to those individuals who have a level of education higher than the most frequent level of education in their occupation); not receiving training from the company; and working in a small company with less than 10 employees. ${ }^{9}$ Eventually, only those characteristics associated with precariousness that negatively affect job satisfaction (and consequently have a statistically significant negative coefficient) are considered as sources of job deficiencies, while the relative weight of each indicator is proportional to the relative magnitude of its standardised beta coefficient obtained in the estimation of the model. ${ }^{10}$ Independent variables also include a full set of control variables related to elements identified in the literature as significant determinants of job satisfaction (see, for instance, Clark, 1996 and 2005 and Clark and Oswald, 1996), which comprise socio-economic attributes (namely gender, age, education, nationality, living with a partner, living with a child, and household income) and characteristics of jobs (length of daily commute, carrying out supervising tasks, seniority in the firm, working in the public sector, and having a continuous work day).

Consequently, Table 1 contains the results of the estimation of the model in which the dependent variable measures the degree of satisfaction of employees with their jobs. As can be observed in the first column, eight out of the ten potential attributes of precarious jobs exhibit negative, significant at conventional levels coefficients and, as a result, they are identified as dimensions of the jobs significantly associated to precariousness. These include earning a relative low wage; having a fixed-term contract; working part-time involuntarily; frequently working longer hours than agreed; frequently working at night, Sundays and shifts; and being overqualified. On the contrary, not receiving training from the company and working in a small company do not affect negatively and significantly job satisfaction. It is worth to mention that the attributes chosen include the three dimensions usually considered in many studies on precariousness (namely, part-time

those produced when it is treated as an ordinal variable in the study of the determinants of individual wellbeing (Ferrer-i-Carbonell and Frijters, 2004 and Dickerson et al., 2014).

${ }^{8}$ The variables and thresholds that have been used to estimate the dimensions of precariousness are highly coincident between the ECVT and the EPA.

9 Although the set of characteristics of the jobs considered include in every case those traditionally highlighted in the literature as related to undesirable attributes of jobs, the possibility of omitted variable bias due to non-inclusion of measures that tap employee contexts and perceptions that are important to the emergence of employment precariousness cannot be discarded.

${ }^{10}$ As is known, the standardized beta coefficients are dimensionless and do not depend on the units of measurement of the variables, so they allow measuring the relative importance of the independent variables in the prediction of the dependent variable, and in its explanation in scenarios of low multicollinearity (for more details, see Nimon and Oswald, 2013, and Kraha et al., 2012). 
work, low-wage employment and temporary work), and that they comprise indicators on a wide range of representative employment characteristics related to precariousness (for more details, see European Foundation for the Improvement of Living and Working Conditions, 1998), including employment status (through two indicators of the type of contract: fixed-term contracts and involuntary part-time work), internal quantitative (extended hours) and qualitative (night work, Sunday work and shift work) flexibility, as well as indicators of quality of life at work (low-wage and overqualification). On the other hand, as can be observed in the final column of the table, the variable inflation factors of the explanatory variables in the model are in every case rather low, so it does not seem that the calculation of the relative weights of the dimensions of precariousness is being affected by the presence of a significant multicollinearity through its effect in the partition of the coefficient of determination.

The second column of Table 1 contains, in turn, the standardized beta coefficients of the dependent variables in the estimation. As can be observed, there exist overall highly relevant differences in the standardized coefficients of job attributes associated to precariousness and, as a result, in the relative weights of each of the dimensions associated to employment precariousness (Table 2). Therefore, the influence of working long hours and, particularly, of having a temporary contract are noteworthy in quantitative terms (with a relative weight of $16 \%$ and $30 \%$ of the total, respectively) whereas, on the contrary, the rest of attributes exhibit a comparatively lower influence. In this vein, it should be noted that the relative weights of other dimensions of precariousness which, together with temporary employment have received preferential attention in the literature, such as earning low wages and working part-time, are, in general, comparable to that of other dimensions, such as overqualification or working at nights or on Sundays.

\section{Results}

Table 3 contains information for the period examined (2006-2015) for each of the eight dimensions considered in the calculation of multidimensional precariousness indexes for Spain and Figure 1 shows the average value of the number of weighted deficiencies $(P)$ of individual jobs. In both cases, this information corresponds to all the salaried jobs existing in the Spanish economy and, alternatively, the newly created jobs in each year (defined as those with less of one year of tenure). The data reveal that both the levels of employment precariousness and its evolution are very different for the two types of jobs. The newly-created jobs exhibit a comparatively high level of average weighted deficiencies (between 2.5 and 3, depending on the year), which duplicates the average number of deficiencies of total jobs (and triples that of pre-existing jobs, namely those with more than one year of tenure). This circumstance is explained by the fact that the proportion of jobs with deficiencies in most of the job attributes is comparatively greater for newly created jobs (for example, in some years the temporariness rate is around $80 \%$, tripling that of total jobs). 
Similarly, the evolution of employment precariousness observed for both types of jobs is also very different. While for newly-created jobs employment precariousness increased significantly due to the economic crisis (the average weighted deficiencies increased from 2.6 to 2.9 between 2006 and 2015), for pre-existing jobs the levels of precariousness remained relatively stable (with around one weighted deficiency on average). This latter circumstance can largely be explained by the fact that the intense destruction of jobs that occurred in Spain during the economic crisis affected particularly unskilled and semiskilled jobs and, as a result, the quality of the jobs not destroyed improved due to a composition effect (OECD, 2013). Consequently, the level of precariousness of total jobs mostly remained stable or grew slightly in the majority of the individual precariousness dimensions (and even fell significantly in some of them: for example, the temporariness rate for total jobs fell from $32.8 \%$ in 2006 to $23.4 \%$ in 2013). As this reduction in job precariousness in a context of labour market deterioration due to the crisis and the implementation of intense changes in labour regulations that reduced the protection of workers is counter-intuitive, in order to avoid possible distortions associated to the influence of composition effects, the rest of the empirical analysis developed in this section will focus exclusively on newly created jobs.

Focusing on this group (bottom panel of Table 3), the presence of deficiencies is generally quite prominent in many of the individual job dimensions (with an incidence of earning low wages of between $20 \%$ and $30 \%$ during the period; temporariness rates systematically higher than $70 \%$ and levels of over-qualification of around 30\%). In addition, it is also observed that an overall deterioration of working conditions was experienced during the period analysed in newly created jobs, with an increase in the presence of deficiencies in roughly all the dimensions. This worsening was particularly apparent in aspects such as the temporariness rate (which increased from $73 \%$ to $80 \%$ ); night work (where the percentage of workers affected rose from $11 \%$ to $20 \%$ ); earning low wages (the incidence of which rose from $22 \%$ to $30 \%$ ) and, particularly, working involuntarily part-time (whose incidence during the period increased from $8.5 \%$ to maximum values of almost $30 \%)$.

Figure 2 presents in turn the values of the aggregated indicators of multidimensional employment precariousness (with their corresponding confidence intervals at 95\%): the rate of multidimensional precariousness $(\widehat{H})$, the standardised average number of deficiencies of precarious jobs $(\hat{A})$, and the adjusted precariousness rate $\left(\widehat{M_{o}}\right)$. They correspond to the use of hedonic weights in the calculation of the number of weighted deficiencies of each individual job $(P)$ and of a value of $k=4$ for the threshold which permits to identify whether a job is precarious from a multidimensional perspective. According to this evidence, during the period analysed highly significant changes occurred in the incidence of multidimensional employment precariousness, given that the multidimensional precariousness rate $(\widehat{H})$ almost doubled. As a result, the percentage of employees in newly created jobs with a precarious employment rose from $10.6 \%$ in 2007 to a maximum of $18.8 \%$ in 2014 . On the contrary, the intensity of precariousness 
(measured using the average standardised number of deficiencies in precarious jobs, $\hat{A}$ ), remained relatively stable, with a weighted average of deficiencies of around 4.8 (representing 60\% of the maximum possible of 8 deficiencies). This circumstance implies that the increases observed in the adjusted multidimensional precariousness rate $\widehat{M}_{o}$ (which corresponds to the product of $\widehat{H}$ and $\hat{A}$ ), were determined almost exclusively by the increases in the incidence of employment precariousness, so that the evolution over time of the values of $\widehat{H}$ and $\widehat{M_{o}}$ is generally very similar.

Consequently, in a similar way for the two latter indicators three differentiated stages can be observed in the evolution of employment precariousness in Spain. During the first stage, corresponding to the growth phase prior to the crisis (2006-2008), precariousness remained relatively stable (the changes observed for $\widehat{H}$ or $\widehat{M_{o}}$ between the years of the afore-mentioned period are in no case statistically significant at conventional levels). The second stage coincides with the initial years of the economic crisis associated to the Great Recession (2009-2011) and is characterised by significant increases in indicators of multidimensional employment precariousness (for example, $\widehat{H}$ grew from 0.103 in 2008 to 0.135 in 2011, with the difference being statistically significant at conventional levels). Finally, the third stage corresponds to the period 2012-2015, characterised by both the negative effects on employment of the crisis associated to the problems of the peripheral economies of the Euro zone such as Spain and the passing of an intense labour reform in Spain at the beginning of 2012, which overall gave rise to a highly significant increase in employment precariousness (namely $\widehat{H}$ and $\widehat{M}_{o}$ reached in 2014 maximum values which roughly doubled those of the period leading up to the crisis). Although these indicators started to decrease during 2015, within the context of the beginning of the current expansion of the Spanish economy, the reduction in their values is not however statistically significant.

As previously indicated, an advantage of the indicator $\widehat{M}_{o}$ is the possibility of knowing the contribution of each of the individual dimensions of the jobs to the adjusted multidimensional precariousness rate. In this vein, Table 4 contains the decomposition of the adjusted precariousness rate of each year in accordance with the participation of each of the unidimensional indicators. Of this evidence, the significant weight of temporariness is particularly noteworthy, which accounts for around half of the values of the total adjusted precariousness rate in all years (it must be noted that this is explained by the joint effect of the high incidence of temporary contracts and the high weight attributed implicitly by employees to temporariness as a determinant of precariousness). On the other hand, the contributions of the rest of the dimensions are comparatively small, generally lower than $10 \%$ and, with very few exceptions, rather similar in all cases. It should be noted that this includes both those attributes which, together with temporariness, have received preferential attention in the literature on employment precariousness (i.e., earning low wages and working part-time) and others which have a comparable influence in practice (such as over-qualification or working on Sundays). 
On another note, in order to illustrate the effects in the empirical analysis of the use of hedonic weights when calculating the multidimensional precariousness indicators, Figure 3 and Table 5 include the values of the aggregate multidimensional precariousness measures $\left(\widehat{H}, \hat{A}\right.$ and $\left.\widehat{M_{o}}\right)$ and the decomposition of the adjusted precariousness rate $\left(\widehat{M_{o}}\right)$ in accordance with the participation of each of the unidimensional indicators of precariousness, alternatively using equal unit weights for each of the dimensions $\left(w_{j}=1\right.$, $\forall j$ ) instead of hedonic weights). The evidence obtained overall suggests that although the time trend of the indicators $\widehat{H}, \hat{A}$ and $\widehat{M_{o}}$ is generally very similar in both cases (consequently, the same phases in the evolution of precariousness between 2006 and 2015 are observed), the levels of precariousness estimated with unit weights are significantly lower, with reductions of around $10 \%$ in the values of $\widehat{H}$ and $\hat{A}$ and of around $20 \%$ for $\widehat{M}_{o}$ (Figure 3). In the same sense, highly significant differences can also be observed in the contributions of the individual dimensions of precariousness to the multidimensional indicator $\widehat{M_{O}}$ (Table 5), being particularly noteworthy the relatively low contribution of temporariness (less than half of that observed with hedonic weights) in detriment to an overall increase of the relative weight of the rest of the dimensions (where a relatively similar influence of both earning low wages and part-time work and of other dimensions such as over-qualification or working on Sundays is observed again).

As previously pointed out, the final part of the empirical analysis consists of using statistical inference techniques to make comparisons of the scope of precariousness between different job distributions. One of the main benefits of these techniques is that they guarantee the robustness of the results of the comparisons between distributions in response to changes both in the multidimensional precariousness indicator and in the values of the cut-off $k$. Accordingly, in Figure 4, the $F D$ curves are represented for some years selected of the period examined. This permits to confirm, for example, that the levels of the incidence of precariousness are apparently generally higher at the end of the period (2015) than at the beginning (2006) for most of the range of values of $k$.

This exploratory analysis, in any case, does not reveal whether the differences between the $F D$ curves are statistically significant and therefore whether dominance exists of some over others, something which must be based on multiple comparison statistical tests for the different values of $k$. In this vein, Table 6 presents the results of the tests corresponding to the comparisons for each combination of years of the overall period analysed of the levels of employment precariousness for the 54 possible values of $k$ (this number of values is the result of the combination of values of the individual attributes of the jobs and their relative weights). With respect to the interpretation of the results, a positive (negative) sign indicates that the year of the column dominates that of the row (that is, the $F D$ curve of the year of the column has greater (lower) or equal values as the $F D$ curve of the year of the row for all the values of $k$ ), which implies that for all values of $\mathrm{k}$, its level of multidimensional precariousness is higher (lower), measured in terms of both the incidence $(\widehat{H})$ and the adjusted precariousness rate $\left(\widehat{M_{o}}\right)$. Meanwhile, an equal sign indicates that there are no significant differences between the compared ordinates, 
so job precariousness would be similar between the two years. In no case significant cuts have been found between the $F D$ curves, a circumstance that would impede us from establishing conclusions about the precariousness of the two distributions compared. Finally, it must be noted that the number of values of $k$ for which significant differences exist between the $F D$ curves of the two compared distributions is shown in brackets.

The results of the comparisons of the $F D$ curves of the job distributions of the different years confirm the important changes in the scope of the employment precariousness in newly created jobs in Spain during the period examined. Therefore, an intense growth in precariousness is observed between the first year of the period (2006) and the final year (2015), with values of the $F D$ curve for the last year being significantly higher for 47 of the 54 possible values of $k .{ }^{11}$ In the same vein, when the early years of the series (20062008) are compared with the rest of the period the number of values of $k$ for which significant positive differences exist increase progressively, which concurs with a significant increase in precariousness. Finally, three phases can be again distinguished in the evolution of employment precariousness, given that there are very few significant differences in the FD curves between the years making up stages 2006-2008 and 20122015 (for example, the null hypothesis of the equality of $F D$ curves when comparing all the years between 2012 and 2015 with each other cannot be rejected), respectively, and significant differences are also found between all the years of each of these two stages and all the years of stage 2009-2011.

\section{Conclusions}

\subsection{Discussion and theoretical implications}

This article examines the evolution of employment precariousness in Spain using a new approach to constructing multidimensional indicators in the context of applying the counting approach technique proposed by Alkire and Foster (2007 and 2011). This novel approach is based on the use of hedonic weights derived from the subjective evaluation by individuals regarding the effect of each individual dimension of jobs on their work dissatisfaction, in order to define which objective job characteristics should be considered as dimensions associated to precariousness and their relative weight when measuring multidimensional precariousness. To the best of our knowledge, the use of a dual approach based on an objective analysis of the characteristics of jobs complemented with a subjective perspective through the estimate of hedonic weights is essentially a novelty in the analysis of employment precariousness. Moreover, it is a flexible approach that may be adapted to different national contexts, which permits an extensive number of dimensions that are not discretionally chosen to be considered, and, in which, as an additional methodological novelty, the robustness of the evidence obtained is confirmed

\footnotetext{
${ }^{11}$ In general, no significant differences can be observed for very high values of $k$, which is largely due to the usually low incidence of extreme precariousness estimated by very high values of $k$.
} 
through the use of function dominance tests in the comparison of the multidimensional precariousness indicators of different periods.

Using this methodological approach, the evolution between 2006 and 2015 of employment precariousness in the Spanish labour market is examined. Spain is a very interesting case study, as it is a country with a very high incidence of employment precariousness from a comparative international perspective, and where the phenomenon may have increased plausibly in recent years, on account of the effects of both the economic crisis and the recent implementation of important regulatory changes which have increased labour flexibility. On the other hand, on an empirical level it is worth pointing out that the analysis focuses on newly-created jobs, given that it better reflects changes in the scope of precariousness employment, and that the multidimensional indicators of precariousness are constructed using two databases, one with information about objective dimensions of the job positions with a sufficiently broad time frame and another which enables to examine the impact of these dimensions on job satisfaction.

The evidence obtained shows that a broad set of job attributes are negatively associated with the job satisfaction of workers and, consequently, should be considered in the multidimensional measurement of employment precariousness. This implies that the limited set of attributes usually considered in the literature (namely fixed-term contracts, low wages and involuntary part-time work) should be extended to include additional job characteristics such as over-qualification or undesirable working hours. In practice, the incidence of fixed-term contracts is identified as a particularly prominent component of multidimensional precariousness, whereas the remaining factors have a relatively similar influence.

From a methodological point of view, the use of hedonic weights in the calculation of multidimensional precariousness indicators gives rise in the case of Spain to significant differences in the results of the examination of the scope of precarious employment, as opposed to the alternative of giving the same relative weight to all the dimensions of the jobs related to precariousness. The observed differences include the identification of both substantially higher levels of precariousness, and very significant differences in the contributions of individual deficiencies to multidimensional precariousness. In the same vein, the use of statistical inference techniques to conduct dominance tests guarantees the robustness of the results of the comparison of employment precariousness between the different years, regardless of the specific values of the threshold used to identify the situation of multidimensional precariousness of each job and the specific multidimensional indicator chosen. Hence, as a result, the article addresses two of the methodological questions considered especially relevant in the construction of composite indices, namely weighting and robustness (see e.g. Greco et al., 2019).

Overall, the evidence obtained suggests that, in a context where the levels of multidimensional employment precariousness were systematically very significant in Spain during the period examined, there was an additional significant increase in the 
scope of the phenomenon that can be explained mostly by its higher incidence. Thus, during the initial years of the economic crisis there was a significant increase in multidimensional employment precariousness, which intensified during the period 20122015 plausibly due to both the negative effects on employment of the second phase of the crisis of the Euro zone and the approval of intense regulatory changes in the Spanish labour market.

\subsection{Policy and managerial implications}

The empirical results arising from this approach to the examination of precarious employment with multidimensional indexes may help policy-makers in the design of specific economic policy measures and the modification of labour market regulations and institutional frameworks in order to reduce the scope of the phenomenon, and to increase inclusive growth and well-being trough the improving of job quality (OECD, 2018). Hence, as a matter of example, obtaining the relative contributions of different dimensions or groups to global precariousness allows targeting specific measures on each of the precariousness dimensions and/or groups. Moreover, in the specific case of Spain, according to the evidence obtained, social policies that aim to reduce the increasingly high levels of precariousness should be focused on reducing the incidence of precariousness on specific dimensions of the employment created, such as fixed-term contracts or involuntary part-time jobs, whose contributions to global precariousness are significant or growing rapidly, respectively.

From the perspective of business managers, especially in the field of human resources, the evidence obtained reveals that some elements of job precariousness are especially relevant to generate job dissatisfaction and therefore to trigger its consequences such as low productivity, absenteeism and the deterioration of the workplace relationships. Hence, for example, in the Spanish case extended hours stands out as a very relevant dimension of precarious employment, which suggests that factors related to the work-life balance seem especially relevant in the labour dissatisfaction perception. In general, the evidence in the article suggests that it is important for firms to understand that workers simultaneously face some conditions that impact their performance in the workplace, and that they can differ greatly depending on the specific national or cultural context. As a result, managers need to be aware of differences in worker preferences and to develop strategies aimed at creating quality jobs and enhancing the work atmosphere, in order to benefit the interests of both the employer and the employee.

\subsection{Limitations of the research}

Our approach is not free of a set of limitations. These are especially related to the data sources required, given that it entails large representative surveys that permit both the measurement of the objective dimensions of jobs and the assessment of their impact on job dissatisfaction, with common definitions and measurements of the dimensions. In the specific case of our empirical analysis, it should be noted that the ECVT, the only survey with information on subjective perceptions of employees in Spain about their job 
satisfaction, was not originally designed with the goal of using job satisfaction for assessing employment precariousness, giving rise to the possibility of the presence of omitted variables bias due to non-inclusion of measures that tap employee contexts and perceptions that are important to the emergence of employment precariousness.

\subsection{Directions for further research}

As for the directions for further research, the multidimensional approach proposed can be used to extend the research on precarious employment in several lines, taking advantage of its flexibility as regards the election of both the dimensions of precariousness and their relative weights. Accordingly, it could be used to examine the scope and determinants of precarious employment by performing comparative international analysis using harmonized information which is currently available in certain regional contexts, such as Europe. Moreover, disaggregated analysis which allow the examination of the scope of precarious employment for especially disadvantaged groups or regions could be carried out in national contexts. Finally, it could also be interesting to examine the causes of employment precariousness using the proposed individual indicators as dependent variables.

\section{References}

Alkire, S., \& Foster, J. (2007). Counting and Multidimensional Poverty Measures. OPHI Working Paper, $\mathrm{n}^{\circ} 7$

Alkire, S., \& Foster, J. (2011). Counting and Multidimensional Poverty Measurement. Journal of Public Economics, 95(7-8), 476-487.

Appelbaum, S., \& Kamal, R. (2001). An analysis of the utilization and effectiveness of nonfinancial incentives in small business. Journal of Management Development, 19(9), 733-63.

Arranz, J. M., García-Serrano, C., \& Hernanz, V. (2018). Employment Quality: Are There Differences by Types of Contract?. Social Indicators Research, 137(1), 203-230.

Bhalla, A., \& McCormick, P. (2009). Poverty among immigrant children in Europe. Springer.

Barbier, J. (2004). A comparative analysis of 'employment precariousness' in Europe. European Research Centre, Cross-National Research Papers, 7, 7-19.

Barbier, J. (2011). "Employment precariousness in a European cross-national perspective - a sociological view over 30 years of research", presented at the May 2011 seminar, De-standardisation of employment, Koln University. 1-39.

Benach, J., Vives, A., Amable, M., Vanroelen, C., Tarafa, G., \& Muntaner, C. (2014). Precarious employment: understanding an emerging social determinant of health. Annual review of public health, 35, 229-253.

Bishop, J. A., Formby, J. P., \& Smith, W. J. (1991). International comparisons of income inequality: Tests for Lorenz dominance across nine countries. Economica, 461-477.

Blau, G. (1994). Developing and testing a taxonomy of lateness behavior. Journal of Applied Psychology, 79, 959-70.

Borooah, V. K. (2009). Comparing levels of job satisfaction in the countries of Western and Eastern Europe. International Journal of Manpower, 30(4), 304-325. 
Boxall, P. (2013). Mutuality in the management of human resources: assessing the quality of alignment in employment relationships. Human Resource Management Journal, 23(1), 3-17.

Bradley, H. and Healy, G. (2008) Ethnicity and gender at work - inequalities, careers and employment relations, Palgrave Macmillan.

Bradley, H., \& Van Hoof, J. (Eds.). (2005). Young people in Europe: Labour markets and citizenship. Policy Press.

Burchell, B., Sehnbruch, K., Piasna, A., \& Agloni, N. (2013). The quality of employment and decent work: definitions, methodologies, and ongoing debates, Cambridge Journal of Economics, 38(2), 459-477.

Burroni, L. Keune, M. (2011). Flexicurity: a conceptual critique, European Journal of Industrial Relations, 17(1), 75-91.

Campbell, I., \& Price, R. (2016). Precarious work and precarious workers: Towards an improved conceptualisation. The Economic and Labour Relations Review, 27(3), 314332.

Clark, A. E. (1996). Job satisfaction in Britain. British Journal of Industrial Relations, $34,189-217$.

Clark, A. E. (2005). What Makes a Good Job? Evidence from OECD Countries. In S. Bazen, C. Lucifora, \&W. Salverda (Eds.), Job Quality and Employer Behaviour (pp. 11-30), ed. Palgrave.

Clark, A. E., \& Oswald, A. J. (1996). Satisfaction and comparison income. Journal of Public Economics, 65, 359-381.

Comi, S., \& Grasseni, M. (2012). Are temporary workers discriminated against? Evidence from Europe. The Manchester School, 80(1), 28-50.

D'Amours, M. (2010). Employment after age 50: How precarious is it? Relations Industrielles/Industrial Relations, 64(2).

Decancq, K., \& Lugo, M. A. (2013). Weights in multidimensional indices of wellbeing: An overview. Econometric Reviews, 32(1), 7-34.

Dickerson, A., Hole, A. R., \& Munford, L. A. (2014). The relationship between wellbeing and commuting revisited: Does the choice of methodology matter?. Regional Science and Urban Economics, 49, 321-329.

Edwards, P., \& Ram, M. (2006). Surviving on the margins of economy: working relationships in small, low-wage firms, Journal of Management Studies, 43 (4), $895-$ 916.

Edwards, P., Sengupta, S., \& Tsai, C. (2009). Managing low-skill workers: a study of UK food manufacturing firms. Human Resource Management Journal, 19(1), 40-58.

European Commission (2011). Employment in Europe Report

European Commission (2017). Country Report Spain 2017 Including an In-Depth Review on the prevention and correction of macroeconomic imbalances.

European Foundation for the Improvement of Living and Working Conditions (1998): Precarious Employment and Working Conditions in Europe.

European Union (2016). Precarious Employment in Europe: Paterns, Trends and Policy Strategies, European Parliament.

Elcioglu, E. (2010). Producing precarity - the temporary staffing agency in the labour market, Qualitative Sociology, 32(2), 117-136.

Evans, J., \& Gibb, E. (2009). Moving from precarious employment to decent work. GURN. 
Fernández-Kranz, D., Paul, M., \& Rodríguez-Planas, N. (2015). Part-time work, fixedterm contracts, and the returns to experience. Oxford Bulletin of Economics and Statistics, 77(4), 512-541.

Ferrer-i-Carbonell, A. \& Frijters, P. (2004). How important is methodology for the estimates of the determinants of happiness?. The Economic Journal, 114, 641-659.

Frade, C., \& Darmon, I. (2005). New modes of business organization and precarious employment: towards the recommodification of labour? Journal of European Social Policy, 15(2), 107-121.

Fudge, J. (1997). Precarious work and families ( $\mathrm{N}^{\circ}$. 15). Centre for Research on Work and Society, York University.

Fudge, J. (2009). Measuring precarious work: the institutional indicators.

Fudge, J., \& Owens, R. (2006). Precarious work, women, and the new economy: The challenge to legal norms. Bloomsbury Publishing.

Fullerton, A. S., Robertson, D. L., \& Dixon, J. C. (2011). Reexamining the Relationship Between Flexibility and Insecurity. In Comparing European Workers Part A (pp. 941). Emerald Group Publishing Limited.

García-Pérez, C., Prieto-Alaiz, M. \& Simón, H. (2017). A New Multidimensional Approach to Measuring Precarious Employment, Social Indicators Research, 134(2), 437-454.

Garrido, M.J., Perez, P., \& Anton, C. (2005). Determinants of sales manager job satisfaction: An analysis of Spanish industrial firms. International Journal of Human Resource Management, 16(1), 1934-54.

Greco, S.; Ishizaka, A.; Tasiou, M.; Torrisi, G. (2019). On the methodological framework of composite indices: A review of the issues of weighting, aggregation, and robustness, Social Indicators Research, 141(1), 61-94.

Guadalupe, M. (2003). The hidden costs of fixed term contracts: the impact on work accidents. Labour Economics, 10(3), 339-357.

Handel, M. J. (2005). Trends in Perceived Job Quality, 1989 to 1998. Work and Occupations, 32, 66-94.

Hirsch, B.T. (2005). Why do Part-Time Workers Earn Less? The Role of Workers and Job Skills, Industrial and Labor Relations Review, 58(4), 525-551.

Horst, D. J., Broday, E. E., Bondarick, R., \& Filippe, L. (2014). Quality of working life and productivity: An overview of the conceptual framework. International Journal of Managerial studies and research, 2(5), 87-98.

Hunt, J.W., \& Saul, P.N. (1975). The Relationship of age, tenure, and job satisfaction in males and females. Academy of Management Journal, 18, 690-702.

ILO (2011), Policies and regulations to combat precarious employment, ILO, Geneva.

Kalleberg, A. (1977). Work values \& job rewards: A theory of job satisfaction. American Sociological Review, 42, 124-43.

Kalleberg, A. (2009). Precarious work, insecure workers: employment relations in transition, American Sociological Review, 74(1), 1-22.

Koonmee, K., Singhapakdi, A., Virakul, B., \& Lee, D. J. (2010). Ethics institutionalization, quality of work life, and employee job-related outcomes: A survey of human resource managers in Thailand. Journal of Business Research, 63(1), 20-26.

Kraha, A., Turner, H., Nimon, K., Zientek, L.R. \& Henson, R.K. (2012). Interpreting multiple regression in the face of multicollinearity. Frontiers in Psychology, 3, 1-10.

Krahn, H. (1995). Non-standard work on the rise. Perspectives on Labour and Income, 7(4), 35-42. 
Kretsos, L. (2010) 'The persistent pandemic of precariousness: young people at work' in J. Tremmel (ed.): A Young Generation Under Pressure?, March, New York: Springer.

Kretsos, L., \& Livanos, I. (2016). The extent and determinants of precarious employment in Europe. International Journal of Manpower, 37(1), 25-43.

Lasso de la Vega, C. (2010). Counting poverty orderings and deprivation curves. In: Bishop, J.A. (Ed.), Studies in Applied Welfare Analysis: Papers from the Third ECINEQ Meeting, Research on Economic Inequality, 18, 153-172. Emerald Group Publishing Limited, Bingley.

Lee, P. K., Lau, A. K., \& Cheng, T. C. E. (2013), Employee rights protection and financial performance, Journal of Business Research, 66(10), 1861-1869.

Lee, T. (1998). Job satisfaction leads to turnover. Journal of Business and Psychology, 2, 263-271.

Leschke, J., Watt, A., \& Finn, M. (2008). Putting a number on job quality? Constructing a European job quality index. ETUI-REHS Working Paper, 2008.

Lewchuk, W., Tambureno, A., Laflèche, M., Procyk, S., Cook, C., Dyson, D., ... \& Viducis, P. (2016). The Precarity Penalty: How Insecure Employment Disadvantages Workers and Their Families. Alternate Routes, 27.

Marta, J. K., Singhapakdi, A., Lee, D. J., Sirgy, M. J., Koonmee, K., \& Virakul, B. (2013). Perceptions about ethics institutionalization and quality of work life: Thai versus American marketing managers. Journal of Business Research, 66(3), 381-389.

McKay, S., Jefferys, S., Paraksevopoulou, A., \& Keles, J. (2012). Study on precarious work and social rights. London: Working Lives Research Institute, London Metropolitan University.

Nardo, M., Saisana, M., Saltelli, A., Tarantola, S., Hoffman, A., \& Giovannini, E. (2005). Handbook on constructing composite indicators.

Nimon, K. \& Oswald, F.L. (2013). Understanding the results of multiple linear regression: beyond standardized regression coefficients. Organizational Research Methods, 16, 650-674.

OECD (2013). The 2012 Labour Market Reform in Spain: A preliminary Assessment.

OECD (2015). Non-standard work, job polarisation and inequality, in OECD, In It Together: Why Less Inequality Benefits All, OECD Publishing, Paris.

OECD (2018). Good Jobs for All in a Changing World of Work. The OECD Jobs Strategy, OECD Publishing, Paris.

Olsthoorn, M. (2014). Measuring precarious employment: A proposal for two indicators of precarious employment based on set-theory and tested with Dutch labor marketdata. Social Indicators Research, 119(1), 421-441.

Perulli, A. (2003). Economically dependent/quasi-subordinate (parasubordinate) employment: legal, social and economic aspects. Study. Brussels: European Commission.

Porthé, V., Ahonen, E., Vázquez, M. L., Pope, C., Agudelo, A. A., García, A. M., ... \& Benach, J. (2010). Extending a model of precarious employment: A qualitative study of immigrant workers in Spain. American journal of industrial medicine, 53(4), 417 424.

Polivka, A. E. (1996). Contingent and alternative work arrangements, defined. Monthly Labor Review, 119(10), 3-9

Quinlan, M., Mayhew, C., \& Bohle, P. (2001). The global expansion of precarious employment, work disorganisation and occupational health: A review of recent research. International Journal of Health Services, 31(2), 335-414. 
Rodgers, G., \& Rodgers, J. (Eds.). (1989). Precarious jobs in labour market regulation: The growth of atypical employment in Western Europe. International Labour Organisation.

Ross, A. (2009). Nice work if you can get it: life and labor in precarious times, New York University Press.

Royuela, V., \& Suriñach, J. (2013). Quality of work and aggregate productivity. Social Indicators Research, 113(1), 37-66.

Schokkaert, E. (2007). Capabilities and satisfaction with life. Journal of Human Development, 8(3), 415-430.

Schokkaert, E., Van Ootegem, L., \& Verhofstadt, E. (2011). Preferences and subjective satisfaction: Measuring well-being on the job for policy evaluation. CESifo Economic Studies, 57(4), 683-714.

Sheen, V. (2010). The social risks of precarious employment for women, Paper presented to International Social Security Association International Policy and Research Conference on Social Security.

Stutzer, A., \& Frey, B.S., 2008. Stress that doesn't pay: the commuting paradox, Scandinavian Journal of Economics, 110 (2), 339-366.

Tangian, A. (2008). Is Europe ready for flexicurity? Empirical evidence, critical remarks and a reform proposal. Intereconomics, 43(2), 99-111.

Tietjen, M.A., \& Myers, R.M. (1998). Motivation and job satisfaction. Management Decision, 36(4), 226-231.

UNECE (2014). Statistical Framework for Measuring Quality of Employment, prepared by the Expert Group on Measuring Quality of Employment. United Nations Economic Commission for Europe.

Vosko, L. (2002). Rethinking feminization: Gendered precariousness in the Canadian labour market and the crisis in social reproduction. Annual Robarts Lecture. Robarts Centre for Canadian Studies.

Vosko, L. (2006). Precarious employment: Understanding labour market insecurity in Canada. Montreal: McGill-Queen's University Press.

Vroom, V. (1964). Work and motivation. New York: Wiley

Westover, J.H. (2008). Potential impacts of globalization on changing job quality and worker satisfaction: A descriptive cross-national comparative examination. Journal of Global Business Management, 4(1), 19-26.

Westover, J.H. (2011). A longitudinal analysis of changing job quality and worker satisfaction in Israel. KCA Journal of Business Management, 3(1), 1-14.

Westover, J. H. (2012). Comparative international differences in intrinsic and extrinsic job quality characteristics and worker satisfaction, 1989-2005. International Journal of Business and Social Science, 3(7).

Westover, J.H., \& Taylor, J. (2010). International differences in job satisfaction: The effects of public service motivation, rewards and work relations. International Journal of Productivity and Performance Management, 59(8), 811-828.

Yalonetzky, G. (2011). Conditions for the Most Robust Poverty Comparisons Using the Alkire-Foster Family of Measures, OPHI Working Papers ophiwp044b, Queen Elizabeth House, University of Oxford. 


\section{Tables and figures}

Figure 1.

Average of the individual weighted precariousness count, $P$.

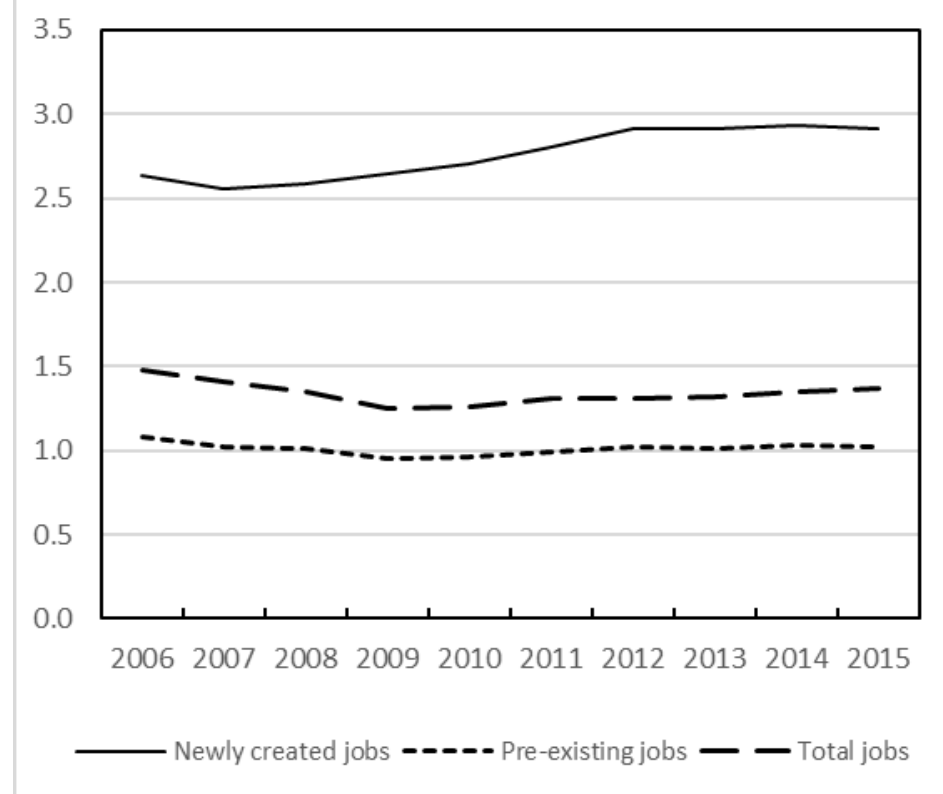


Figure 2.

Aggregate measures of multidimensional precariousness: $\hat{A}$ (right scale), $\widehat{H}$ and $\widehat{M_{o}}$ (left scale). Newly created jobs. Hedonic weights in the calculation of $P$ and $k=4$.

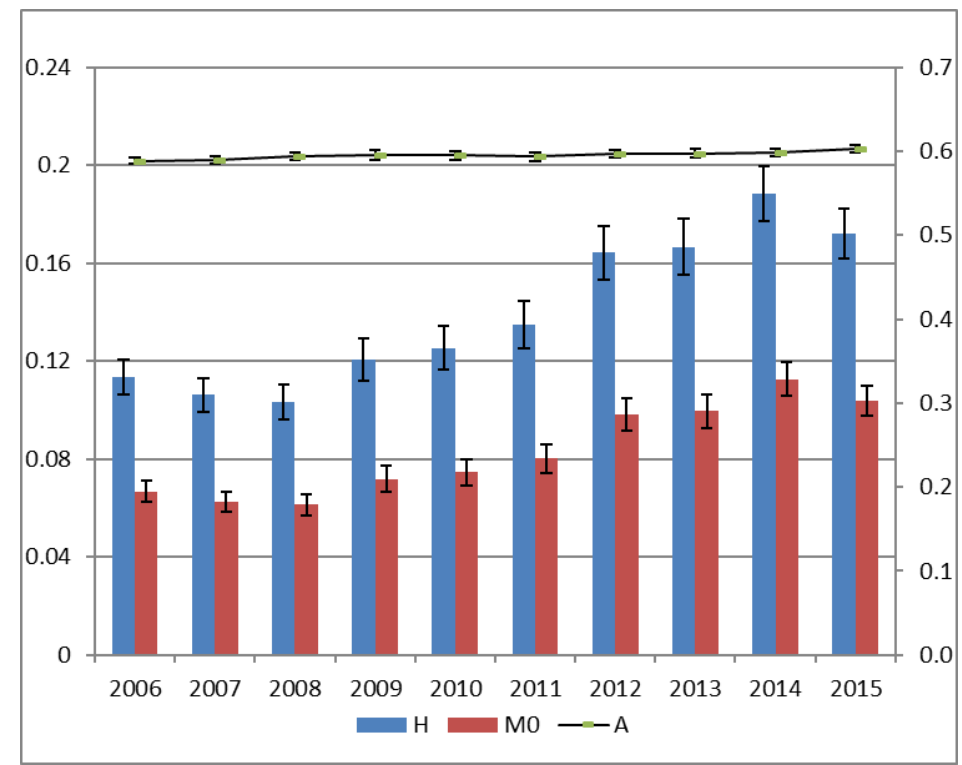


Figure 3.

Aggregate measures of multidimensional precariousness: $\hat{A}$ (right scale), $\widehat{H}$ and $\widehat{M_{o}}$ (left scale). Newly created jobs. Unit weights in the calculation of $P$ and $k=4$.

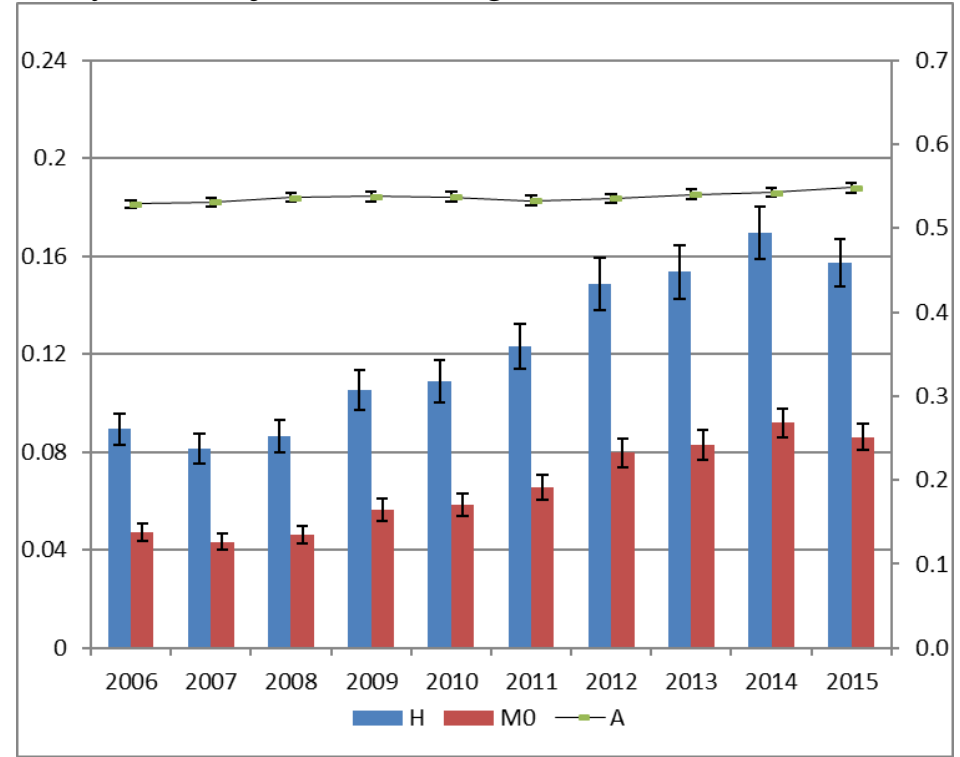


Figure 4.

$F D$ curves.

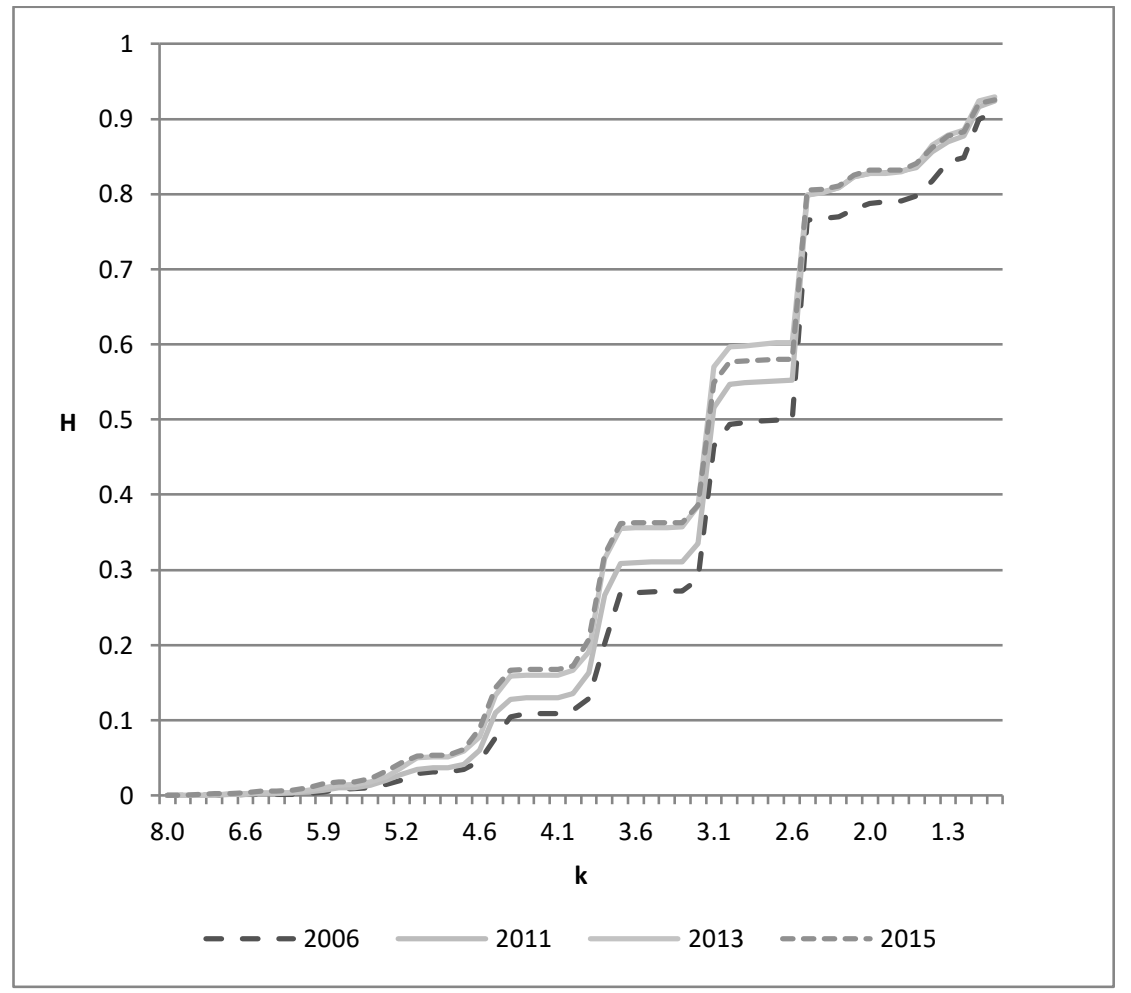


Table 1.

Determinants of job satisfaction for Spanish employees.

\begin{tabular}{|c|c|c|c|}
\hline & Coefficient & $\begin{array}{c}\text { Standardized } \\
\text { beta } \\
\text { coefficient }\end{array}$ & $\begin{array}{c}\text { Variance } \\
\text { Inflation } \\
\text { Factor } \\
\end{array}$ \\
\hline Earning a low-wage & $\begin{array}{c}-0.171 \\
(0.055)^{* * *}\end{array}$ & -0.024 & 1.34 \\
\hline Fixed-term contract & $\begin{array}{c}-0.361 \\
(0.030)^{* * *}\end{array}$ & -0.083 & 1.24 \\
\hline Involuntary part-time work & $\begin{array}{c}-0.152 \\
(0.047)^{* * *}\end{array}$ & -0.025 & 1.26 \\
\hline Extended hours & $\begin{array}{c}-0.163 \\
(0.031)^{* * *}\end{array}$ & -0.044 & 1.12 \\
\hline Overqualification & $\begin{array}{c}-0.259 \\
(0.042)^{* * *}\end{array}$ & -0.024 & 1.22 \\
\hline Night work & $\begin{array}{c}-0.125 \\
(0.038) * * *\end{array}$ & -0.028 & 1.40 \\
\hline Work on Sundays & $\begin{array}{c}-0.083 \\
(0.028)^{* * *}\end{array}$ & -0.026 & 1.35 \\
\hline Work in shifts & $\begin{array}{c}-0.052 \\
(0.010) * * *\end{array}$ & -0.019 & 1.41 \\
\hline Firm with less than 10 employees & $\begin{array}{l}-0.067 \\
(0.056)\end{array}$ & -0.012 & 1.37 \\
\hline Not receiving training from the company & $\begin{array}{l}-0.039 \\
(0.055)\end{array}$ & -0.009 & 1.25 \\
\hline Woman & $\begin{array}{c}0.122 \\
(0.023)^{* * *}\end{array}$ & 0.034 & 1.18 \\
\hline Age & $\begin{array}{c}-0.055 \\
(0.008)^{* * *}\end{array}$ & -0.336 & 2.17 \\
\hline Native & $\begin{array}{c}-0.143 \\
(0.038)^{* * *}\end{array}$ & -0.037 & 2.30 \\
\hline Secondary education & $\begin{array}{c}-0.080 \\
(0.034)^{* *}\end{array}$ & -0.023 & 2.25 \\
\hline University education & $\begin{array}{c}-0.091 \\
(0.039)^{* *}\end{array}$ & -0.025 & 2.46 \\
\hline Lives with partner & $\begin{array}{c}0.074 \\
(0.028)^{* * *}\end{array}$ & 0.024 & 1.44 \\
\hline Lives with child under 15 years old & $\begin{array}{c}0.045 \\
(0.027)^{*}\end{array}$ & 0.012 & 1.30 \\
\hline Household income (/1000) & $\begin{array}{c}0.000 \\
(0.000)^{* * *}\end{array}$ & 0.070 & 1.41 \\
\hline Length of daily commute/60 & $\begin{array}{c}-0.401 \\
(0.038) * * *\end{array}$ & -0.075 & 1.07 \\
\hline Seniority in the firm & $\begin{array}{c}-0.007 \\
(0.001)^{* * *}\end{array}$ & -0.040 & 1.81 \\
\hline Supervising tasks & $\begin{array}{c}0.266 \\
(0.027)^{* * *}\end{array}$ & 0.061 & 1.17 \\
\hline Continous work day & $\begin{array}{c}-0.106 \\
(0.024) * * *\end{array}$ & -0.032 & 1.24 \\
\hline Public sector & $\begin{array}{c}0.285 \\
(0.027)^{* * *}\end{array}$ & 0.070 & 1.29 \\
\hline Constant & $\begin{array}{c}8.393 \\
(0.160)^{* * *}\end{array}$ & - & - \\
\hline $\mathrm{R}^{2}$ & 0.321 & & \\
\hline$N$ & 25,964 & & \\
\hline
\end{tabular}


Table 2.

Relative weights of individual dimensions of employment precariousness.

\begin{tabular}{lc}
\hline \multicolumn{1}{c}{ Dimension } & Weight \\
\hline Earning low-wage & 0.696 \\
Fixed-term contract & 2.435 \\
Involuntary part-time work & 0.730 \\
Extended hours & 1.287 \\
Overqualification & 0.696 \\
Night work & 0.835 \\
Work on Sundays & 0.765 \\
Work in shifts & 0.557 \\
\multicolumn{1}{c}{ Total } & 8 \\
\hline \multicolumn{1}{c}{}
\end{tabular}


Table 3.

Proportion of jobs (\%) with deficiencies in each labour dimension.

\begin{tabular}{lrrrrrrrrrr}
\hline Total jobs & 2006 & 2007 & 2008 & 2009 & 2010 & 2011 & 2012 & 2013 & 2014 & 2015 \\
\hline Earning low-wage & 11.1 & 10.8 & 10.0 & 9.8 & 9.1 & 10.0 & 10.5 & 10.8 & 11.0 & 10.6 \\
Fixed-term contract & 32.8 & 30.3 & 28.8 & 24.7 & 24.5 & 25.2 & 23.9 & 23.4 & 24.2 & 25.4 \\
Involuntary part-time work & 4.6 & 4.5 & 4.9 & 6.7 & 7.5 & 8.9 & 10.3 & 11.6 & 11.7 & 11.4 \\
Extended hours & 14.0 & 13.5 & 12.6 & 10.9 & 10.3 & 9.8 & 10.4 & 11.0 & 11.1 & 9.7 \\
Overqualification & 24.2 & 23.7 & 22.9 & 22.9 & 23.4 & 24.2 & 25.6 & 25.8 & 26.9 & 27.5 \\
Night work & 5.3 & 5.0 & 5.3 & 5.6 & 6.1 & 6.3 & 6.1 & 6.0 & 6.0 & 6.1 \\
Work on Sundays & 10.9 & 10.8 & 11.6 & 12.5 & 13.6 & 14.3 & 14.8 & 14.1 & 15.1 & 15.8 \\
Work in shifts & 16.9 & 17.0 & 16.4 & 15.9 & 17.6 & 17.9 & 18.3 & 18.7 & 18.5 & 18.8 \\
\hline Newly created jobs & & & & & & & & & & \\
\hline Earning low-wage & 23.0 & 22.1 & 21.7 & 22.4 & 22.2 & 24.0 & 28.0 & 30.3 & 28.3 & 27.7 \\
Fixed-term contract & 75.7 & 73.4 & 74.3 & 74.9 & 76.9 & 79.0 & 79.8 & 79.1 & 79.2 & 79.9 \\
Involuntary part-time work & 8.9 & 8.5 & 10.0 & 16.3 & 16.6 & 21.0 & 26.7 & 29.6 & 25.6 & 24.0 \\
Extended hours & 12.2 & 11.1 & 9.8 & 8.4 & 7.9 & 7.4 & 7.6 & 6.7 & 8.2 & 7.1 \\
Overqualification & 30.7 & 28.9 & 27.4 & 28.1 & 29.7 & 32.0 & 33.6 & 33.7 & 33.7 & 33.3 \\
Night work & 11.3 & 11.8 & 14.2 & 16.2 & 16.6 & 15.9 & 17.3 & 16.7 & 19.3 & 19.5 \\
Work on Sundays & 22.6 & 22.4 & 23.1 & 24.3 & 25.0 & 25.1 & 26.2 & 25.5 & 26.6 & 27.1 \\
Work in shifts & 15.4 & 15.6 & 15.1 & 14.5 & 14.5 & 14.8 & 15.5 & 15.4 & 16.7 & 16.9 \\
\hline Total jobs & 33,260 & 34,393 & 34,210 & 32,509 & 32,870 & 31,288 & 30,980 & 29,169 & 29,589 & 30,811 \\
\% Newly created/Total jobs & 22.7 & 22.3 & 19.8 & 16.2 & 15.6 & 15.5 & 14.1 & 14.2 & 15.7 & 17.3 \\
\hline & & & & & & & & & & \\
\hline
\end{tabular}


Table 4.

Contribution (\%) of individual dimensions to the adjusted precariousness rate $\left(\widehat{M_{o}}\right)$. Newly created jobs. Hedonic weights in the calculation of $P$ and $k=4$.

\begin{tabular}{cccccccccc}
\hline & $\begin{array}{c}\text { Low- } \\
\text { wage }\end{array}$ & $\begin{array}{c}\text { Fixed- } \\
\text { term } \\
\text { contract }\end{array}$ & $\begin{array}{c}\text { Involuntary } \\
\text { part-time }\end{array}$ & $\begin{array}{c}\text { Extended } \\
\text { hours }\end{array}$ & Overqual. & $\begin{array}{c}\text { Night } \\
\text { work }\end{array}$ & Sundays & Shifts & Total \\
\hline 2006 & 8.9 & 51.4 & 4.6 & 11.1 & 8.2 & 4.0 & 6.9 & 4.8 & 100 \\
2007 & 8.6 & 51.3 & 3.9 & 11.4 & 7.9 & 5.0 & 7.2 & 4.7 & 100 \\
2008 & 8.5 & 50.4 & 4.9 & 9.3 & 7.8 & 5.8 & 8.6 & 4.6 & 100 \\
2009 & 8.9 & 50.8 & 6.9 & 7.1 & 8.1 & 5.4 & 8.3 & 4.5 & 100 \\
2010 & 8.5 & 51.0 & 6.6 & 7.0 & 7.6 & 5.8 & 9.1 & 4.4 & 100 \\
2011 & 9.2 & 50.9 & 8.3 & 6.2 & 8.5 & 4.7 & 7.7 & 4.5 & 100 \\
2012 & 9.6 & 50.7 & 8.3 & 6.7 & 8.4 & 4.0 & 8.1 & 4.1 & 100 \\
2013 & 10.2 & 50.6 & 9.2 & 5.6 & 8.2 & 4.1 & 7.5 & 4.6 & 100 \\
2014 & 9.3 & 50.6 & 8.5 & 5.7 & 8.7 & 4.1 & 8.7 & 4.3 & 100 \\
2015 & 9.2 & 50.0 & 8.3 & 5.4 & 8.9 & 4.7 & 8.9 & 4.7 & 100 \\
\hline
\end{tabular}


Table 5.

Contribution (\%) of individual dimensions to the adjusted precariousness rate $\left(\widehat{M}_{o}\right)$. Newly created jobs. Unit weights in the calculation of $P$ and $k=4$.

\begin{tabular}{lccccccccc}
\hline & $\begin{array}{c}\text { Low- } \\
\text { wage }\end{array}$ & $\begin{array}{c}\text { Fixed- } \\
\text { term } \\
\text { contract }\end{array}$ & $\begin{array}{c}\text { Involuntary } \\
\text { part-time }\end{array}$ & $\begin{array}{c}\text { Extended } \\
\text { hours }\end{array}$ & Overqual. & $\begin{array}{c}\text { Night } \\
\text { work }\end{array}$ & Sundays & Shifts & Total \\
\hline 2006 & 16.2 & 22.2 & 9.0 & 6.2 & 15.0 & 6.6 & 12.4 & 16.2 & 100 \\
2007 & 15.7 & 22.1 & 8.2 & 5.9 & 14.7 & 8.0 & 13.2 & 15.7 & 100 \\
2008 & 15.3 & 21.7 & 9.3 & 5.2 & 13.7 & 8.9 & 14.7 & 15.3 & 100 \\
2009 & 16.1 & 22.0 & 12.5 & 4.1 & 14.4 & 7.4 & 13.3 & 16.1 & 100 \\
2010 & 15.7 & 21.9 & 11.9 & 4.2 & 13.3 & 8.1 & 14.5 & 15.7 & 100 \\
2011 & 16.2 & 22.3 & 13.8 & 4.0 & 15.1 & 6.5 & 11.9 & 16.2 & 100 \\
2012 & 17.2 & 22.4 & 14.5 & 4.1 & 14.4 & 5.3 & 12.4 & 17.2 & 100 \\
2013 & 17.4 & 22.3 & 15.4 & 3.6 & 14.4 & 5.3 & 11.2 & 17.4 & 100 \\
2014 & 16.7 & 22.1 & 14.5 & 3.4 & 15.5 & 4.9 & 13.3 & 16.7 & 100 \\
2015 & 16.0 & 22.1 & 13.7 & 3.1 & 14.7 & 6.4 & 13.7 & 16.0 & 100 \\
\hline
\end{tabular}


Table 6.

Dominance tests of $F D$ curves.

\begin{tabular}{|c|c|c|c|c|c|c|c|c|c|}
\hline & 2007 & 2008 & 2009 & 2010 & 2011 & 2012 & 2013 & 2014 & 2015 \\
\hline 2006 & $-(7)$ & $-(6)$ & $+(2)$ & $+(4)$ & $+(27)$ & $+(44)$ & $+(41)$ & $+(43)$ & $+(47)$ \\
\hline 2007 & & $=(0)$ & $+(15)$ & $+(26)$ & $+(34)$ & $+(44)$ & $+(45)$ & $+(44)$ & $+(50)$ \\
\hline 2008 & & & $+(3)$ & $+(11)$ & $+(33)$ & $+(38)$ & $+(39)$ & $+(43)$ & $+(49)$ \\
\hline 2009 & & & & $=(0)$ & $+(23)$ & $+(38)$ & $+(37)$ & $+(37)$ & $+(38)$ \\
\hline 2010 & & & & & $+(7)$ & $+(28)$ & $+(20)$ & $+(27)$ & $+(29)$ \\
\hline 2011 & & & & & & $+(14)$ & $+(19)$ & $+(27)$ & $+(22)$ \\
\hline 2012 & & & & & & & $=(0)$ & $+(2)$ & $=(0)$ \\
\hline 2013 & & & & & & & & $=(0)$ & $=(0)$ \\
\hline 2014 & & & & & & & & & $=(0)$ \\
\hline
\end{tabular}

Notes: A positive (negative) sign in a cell indicates that the $F D$ curve of the year of the row dominates (is dominated by) that of the year of the column. In parentheses appears the number of ordinates with significant differences. The symbol = indicates that no significant differences are detected between the $F D$ curves of the years that are compared, so there is no dominance. The level of significance used in the contrasts is $1 \%$. 